\title{
Bimetallic Cooperativity with a 2-Phosphinoimidazole-Derived Pd(II) Dimer Enables Naphthalene Synthesis via dimeric Pd(III) Catalysis
}

\author{
Chloe C. Ence, S. Hadi Nazari, † Mariur Rodriguez Moreno, Manase F. Matu, Samantha G. Kulka, Erin \\ E. Martinez, Kyle J. Gassaway, Gabriel A. Valdivia-Berroeta, ${ }^{\dagger}$ Stacey J. Smith, Daniel H. Ess, David J. \\ Michaelis*
}

aDepartment of Chemistry and Biochemistry, Brigham Young University, Provo, Utah 84602, United States

Palladium(II) dimer, bimetallic catalysis, alpha-arylation, naphthalene

\begin{abstract}
We report the synthesis of bimetallic Pd(I) and Pd(II) complexes scaffolded on bidentate 2-phosphinoimidazole ligands. These complexes display unique catalytic activity and enable the expeditious formation of 1,3-disubstituted naphthalenes via an unprecedented coupling of aryl iodides and methyl ketones in the presence of silver triflate. Excellent substrate scope for naphthalene formation is also demonstrated. Mechanistic studies suggest that the transformation proceeds via Pd-catalyzed arylation of a methyl ketone, followed by cyclization with a second equivalent of ketone. Importantly, this ketone arylation processes occurs under oxidizing conditions, suggesting involvement of higher oxidation state dimeric Pd catalysts. Based on experiments and DFT calcula-

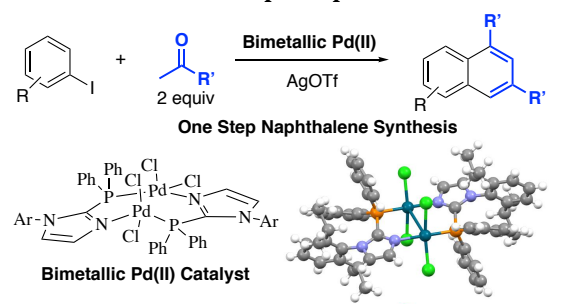
tions, we propose a mechanism involving high oxidation state Pd(III) bimetallic catalysis. These new bimetallic complexes possess reactivity that is not seen with monometallic Pd catalysts and we confirm the importance of the palladium catalyst for both arylation and cyclization for naphthalene formation.
\end{abstract}

The synthesis of homo- and heterobimetallic transition metal complexes provides an innovative and productive approach to catalyst development because of the unique reactivity that often results from inter-metal cooperativity. ${ }^{1}$ The classic example of this type of cooperative benefit is observed in dirhodium tetracarboxylate catalysis, where the presence of a second rhodium center facilitates the formation of higher oxidation state Rh(IV) intermediates in carbene catalysis. ${ }^{2}$ More recent examples of synthetically useful bimetallic complexes include work from the Mankad group on $\mathrm{Cu}-\mathrm{Fe} \mathrm{C}-\mathrm{H}$ borylations, ${ }^{3}$ the Lu group on $\mathrm{Ni}-\mathrm{M}$ hydrogenations, ${ }^{4}$ the Uyeda group on $\mathrm{Ni}-\mathrm{Ni}$ cycloaddition reactions, ${ }^{5}$ and our group on Pd-Ti allylic aminations, ${ }^{6}$ among others. $^{7}$ Each of these examples of bimetallic catalysis achieve increased efficiency and selectivity or new reaction mechanisms that cannot be accessed in single-metal catalytic systems.

One significant advantage of having two metals participate in a catalytic process is the opportunity to access unique oxidation states and undergo binuclear mechanistic steps that enable new types of reactivity. For example, in the $\mathrm{Cu}-\mathrm{Fe}$ catalyzed $\mathrm{C}-\mathrm{H}$ borylations by Mankad, ${ }^{3}$ binuclear reductive elimination is proposed to enable catalyst turnover and reformation of the active $\mathrm{Cu}-\mathrm{Fe}$ species. ${ }^{8}$ In addition, palladium(III) dimers have been confirmed as active catalytic species in oxidative transformations under palladium catalysis. ${ }^{9}$ Sanford and Ritter have suggested that formation of palladium (III) dimers helps facilitate binuclear oxidative addition and reductive elimination, which helps eliminate the need to access high energy Pd(IV) intermediates (Figure 1a). ${ }^{10}$ Hartwig, Schoenebeck, Hazari, and others have also developed a diverse set of $\mathrm{Pd}(\mathrm{I})$ dimer catalysts that

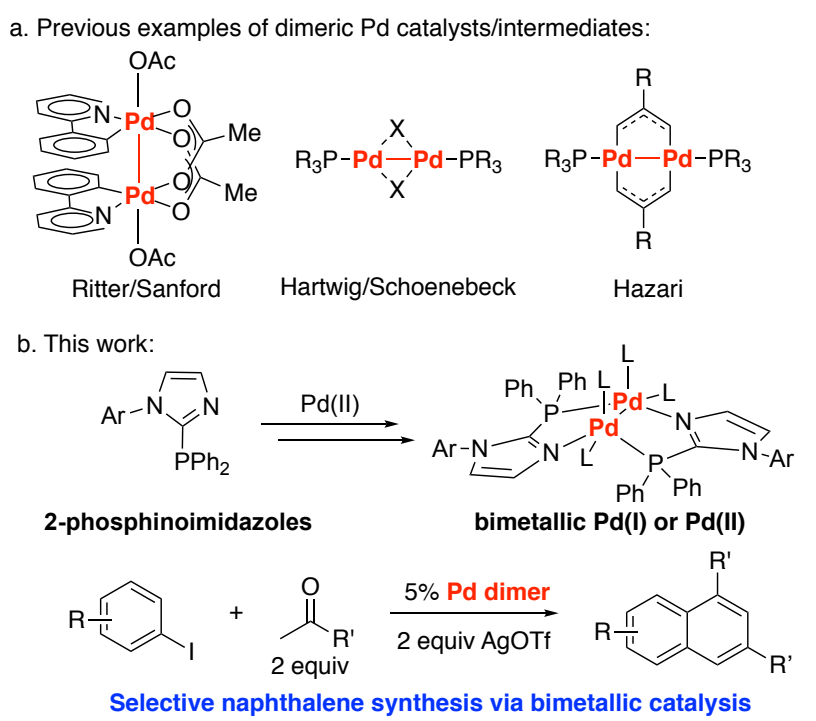

Figure 1. Dimeric Pd complexes for catalysis. 
efficiently perform a range of cross coupling reactions, including for Suzuki, Negishi, Sonogashira, and BuchwaldHartwig amination reactions. ${ }^{11}$

Our research efforts are focused on the development of new ligand frameworks capable of assembling catalytically active bimetallic complexes. Previous work from our group, and Nagashima, demonstrated and quantified the exceptional reactivity of datively interacting bimetallic Pd-Ti catalysts for allylic amination reactions, including chiral complexes for enantioselective allylic aminations. ${ }^{6}$ Recently, we became interested in 2-phosphinoimidazole ligands because of their unique $\mathrm{P}-\mathrm{N}$ bidentate structure that we believed could enable formation of homo- and heterobimetallic complexes capable of catalysis. Indeed, several previous reports have demonstrated the formation of palladium(II) dimers when specific palladium precursors were ligated to the 2-phosphinoimidazole ligand framework. ${ }^{12}$ In this study, we report the synthesis of both $\mathrm{Pd}(\mathrm{I})$ and $\mathrm{Pd}(\mathrm{II}) \mathrm{di}-$ mers using 2-phosphinoimidazole ligand scaffolds (Figure 1b). In catalytic studies, we show that these complexes enable a previously unknown tandem reaction process that couples two equivalents of a methyl ketone with an aryl iodide to generate 1,3-disubstituted naphthalene products in high yield. The dinuclear palladium catalysts are proposed to enable formation of a key Pd(III) dimer during catalysis via oxidative addition with an aryl halide. The Pd(III) dimer then facilitates formation of ketone arylation products via bimetallic reductive elimination, followed by cyclization and aromatization to form a new naphthalene product. DFT calculations support our hypothesis that the bimetallic complex remains intact during this transformation.

Our studies began with the attempt to isolate new dimeric palladium complexes from 2-diphenylphosphino-1-arylimidazole ligands. We found that the identity of both the ligand and the palladium precursor had a significant impact on the final structure of the complex obtained. For example, when ligand 1 was mixed with $\mathrm{PdCl}_{2}$ in methanol, a new monomeric Pd complex (2) was obtained where the palladium had inserted between the $\mathrm{P}-\mathrm{C}$ bond of the ligand (Figure

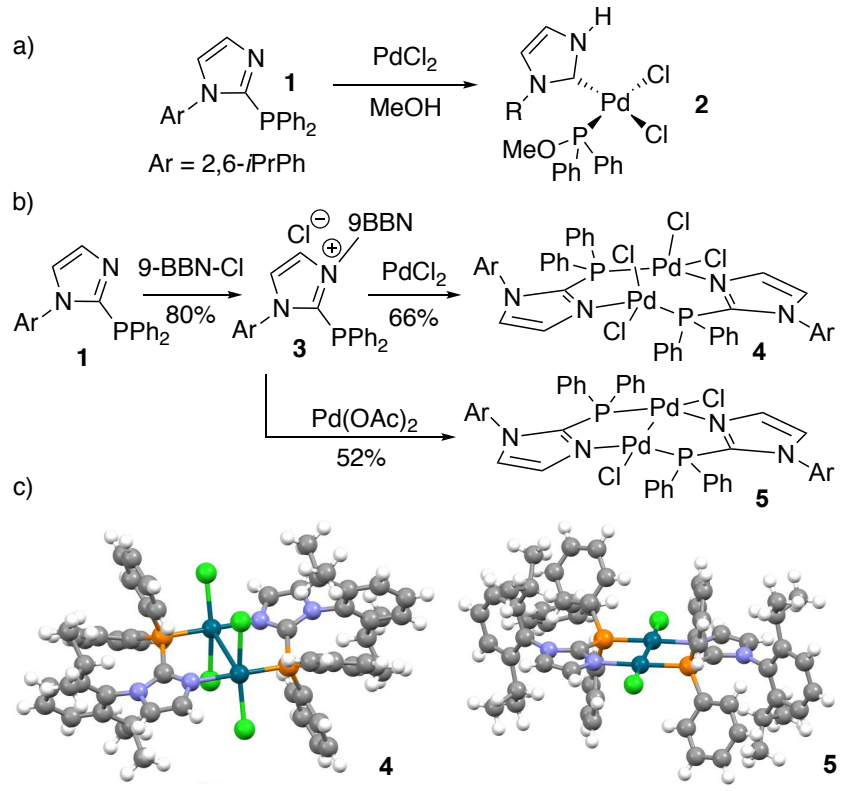

Figure 2. Synthesis and structure of bimetallic Pd complexes. 2a). We recently demonstrated that this $\mathrm{N}-\mathrm{H}$ NHC palladium complex is highly active in palladium-catalyzed Suzuki-Miyaura reactions. ${ }^{13}$ In contrast, we found that if ligand $\mathbf{1}$ was first coordinated with a boron Lewis acid to form $\mathbf{3}$, formation of a dimeric Pd(II) complex (4) was observed selectively upon addition of $\mathrm{PdCl}_{2}$ (Figure 2b).

Dimeric Pd(II) complexes similar to complex 4 have been previously reported by Diez et. al, but required the use of $\mathrm{PdMeCl}$ as precursor in order to obtain the bimetallic structure. ${ }^{12 a}$ Alternatively, if $\mathrm{Pd}(\mathrm{OAc})_{2}$ was employed instead of $\mathrm{PdCl}_{2}$, a $\mathrm{Pd}(\mathrm{I})$ dimer (5) was selectively obtained. We believe that the presence of the boron ligand may help facilitate faster ligand coordination via a transmetallation-like mechanism. For example, when ligand $\mathbf{3}$ is added to $\mathrm{PdCl}_{2}$, complex 4 is generated in 66\% yield after $18 \mathrm{~h}$. However, when ligand $\mathbf{1}$ is employed that does not contain the boron Lewis acid, complex 4 is isolated in $43 \%$ yield after 3 days.

The crystal structures of these bimetallic palladium complexes provide additional insights into their structure and reactivity (Figure 2c). In $\mathrm{Pd}(\mathrm{II})$ dimer 4, the two palladium centers are held within the Van der Waals contact distance for a Pd-Pd bond, but the absence of unpaired electrons prevents Pd-Pd bond formation (Pd-Pd distance $=2.966 \AA$ ). Thus, the two palladium centers are distorted out of a true square planar geometry likely to try to avoid interactions between the two filled $\mathrm{dz}^{2}$ orbitals on each palladium. This distorted geometry in complex $\mathbf{4}$, we believe, may lead to unique reactivity such as rapid oxidation to a Pd(III) dimer in order to relieve this repulsion between the two palladium centers (vide infra). For $\mathrm{Pd}(\mathrm{I})$ dimer 5, the presence of unpaired electrons on each palladium center serves as a driving force for $\mathrm{Pd}-\mathrm{Pd}$ bond formation (Pd-Pd distance $=2.591$ $\AA$ ). The square planar geometry of the two palladium centers and their oxidation states are also consistent with metal-metal bond formation. Indeed, the DFT computed orbitals for $\mathbf{4}$ and $\mathbf{5}$ confirmed our description. As shown in Figure 3, 4 lacks direct Pd-Pd covalent bonding and the HOMO consists mainly of the two $\mathrm{d}_{\mathrm{z}}^{2}$ orbitals interacting in an antibonding fashion. The HOMO of Pd(I) dimer 5, in contrast, shows a direct $\mathrm{Pd}-\mathrm{Pd}$ covalent interaction.

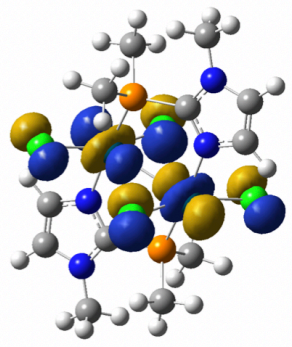

HOMO (4)

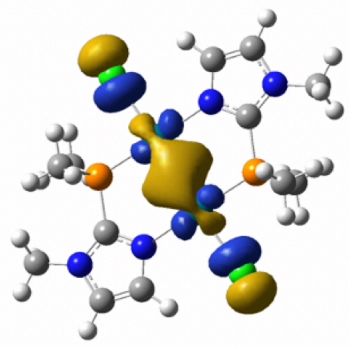

HOMO (5)
Figure 3. M06/6-31G**[LANL2DZ]-calculated HOMOs for complexes $\mathbf{4}$ and 5. ${ }^{14,15}$

Our next goal was to determine the catalytic potential of these new dimeric palladium complexes. While exploring their activity under various conditions, we discovered a multistep reaction process that has not previously been reported. This unique transformation employs an aryl iodide and 2 equivalents of a methyl ketone to generate 1,3-distubstituted naphthalene products (6) under oxidative condi- 
tions with 2 equiv AgOTf (Figure 4). While synthetic approaches to 1,3-disubstituted naphthalenes have been demonstrated previously, they generally require multistep syntheses to access cyclization precursors such as intermediates $\mathbf{7}, \mathbf{8}, \mathbf{9}$, or $\mathbf{1 0},{ }^{16}$ our newly discovered transformation enables direct access to 1,3-disubstituted naphthalenes in a single step from commercially available aryl iodides and methyl ketones. This expeditious approach to naphthalene core structures is significant because naphthalenes have a variety of technological and pharmacological uses, ${ }^{17}$ including as templates to construct carbon nanotubes ${ }^{18}$ and as proton conducting solid electrolytes. ${ }^{19}$ In addition to the synthetic value of this new transformation, it also provides an opportunity to investigate bimetallic cooperativity and its impact on catalysis, as monometallic palladium catalysts do not achieve the same levels of reactivity as complexes 4 and 5.

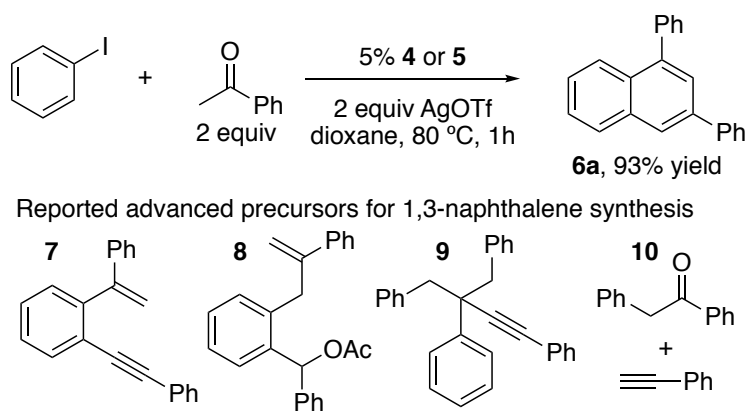

Figure 4. Approaches to 1,3-disubstituted naphthalenes.

Our catalyst optimization studies probed the impact of different Lewis acids, temperatures, ligands, and solvents on the reaction efficiency (Table 1). Under our optimized conditions with 2.5 equivalents ketone, 2 equivalents of AgOTf, in dioxane at $80{ }^{\circ} \mathrm{C}$, the reaction proceeded to $100 \%$ conversion with bimetallic complexes $\mathbf{4}$ and $\mathbf{5}$ and provided $89 \%$ and $84 \%$ yield of the naphthalene product, respectively (entries 1 and 2). In addition, we found that simply pre-stirring ligand 3 with $\mathrm{PdCl}_{2}$ or $\mathrm{Pd}(\mathrm{OAc})_{2}$ in dioxane for 15 minutes led to the formation of bimetallic complexes 4 and 5, as observed by 31P NMR. This in situ-formed catalysts had the same catalytic activity as preformed complexes 4 and 5 (entries 3-4). Varying the Lewis acid in the reaction demonstrated that while $\mathrm{Cu}(\mathrm{OTF})$ provided the desired product in good yield, the reaction time was greatly extended (entry 5). Other iron- or copper-based Lewis acids failed to enable product formation (entries 6-8). We next explored the impact of other ligands on the reaction and found that ligand 1, which lacks the boron Lewis acid, gives much lower yield (entry 9), presumably due to formation of lower concentrations of the active catalyst species. In addition, $\mathrm{N}$-arylimidazole ligands that lack both the boron and 2-diphenylphosphino groups provide no product in the reaction (entry 10). We also screened other mono- and bidentate ligands and found that while $\mathrm{PPh}_{3}$ as a ligand provided a small amount of product, bisphosphines and diamine ligands did not provide any product formation (entries 1115). In additional optimization studies, we found that dioxane was the optimal solvent for the reaction and that dropping the reaction temperature below $80{ }^{\circ} \mathrm{C}$ lead to a de- crease in the yield (see supporting information for full optimization details). The reaction also shuts down completely with added TfOH ( 2 equiv), suggesting that $\mathrm{TfOH}$ is not participating in the cyclization mechanism (entry 16). When the palladium is left out of the reaction (entry 17), no product is observed.

Having established optimal reaction conditions for naphthalene formation, we next explored the substrate scope of the reaction with respect to the aryl iodide coupling partner (Figure 5). For 4-substituted iodoarenes, we only ever observed a single isomer for addition of the two acetophenone molecules. Thus, the 1,3-disubstituted naphthalene product contains a phenyl group beta to the carbon that originally contained the iodide (6b-6g). Aryl iodides containing substituents at either the meta- (6i-6l) or ortho-positions (6m-6o) also react to give the naphthalene products in high yield. Aryl iodides with meta Substituents also provided only a single observed regioisomer, where cyclization oc

Table 1. Optimization of reaction conditions.

\begin{tabular}{|c|c|c|c|c|}
\hline & $\begin{array}{r}\mathrm{O} \\
+\quad 1 \\
2.5 \mathrm{ec}\end{array}$ & $\underset{\text { dioxane, } 80^{\circ} \mathrm{C}}{2 \text { equiv oxidant }}$ & & \\
\hline entry ${ }^{a}$ & Lewis acid & Cat. & time & $\%$ conv. \\
\hline 1 & AgOTf & Complex 4 & $1 \mathrm{~h}$ & 100 (89) \\
\hline 2 & AgOTf & Complex 5 & $1 \mathrm{~h}$ & $100(84)$ \\
\hline 3 & AgOTf & $\mathrm{Pd}(\mathrm{OAc})_{2}+\mathbf{3}$ & $1 \mathrm{~h}$ & $100(90)$ \\
\hline 4 & AgOTf & $\mathrm{PdCl}_{2}+\mathbf{3}$ & $1 \mathrm{~h}$ & 100 (93) \\
\hline 5 & CuOTf & $\mathrm{PdCl}_{2}+3$ & $16 \mathrm{~h}$ & 85 \\
\hline 6 & FeOTf & $\mathrm{PdCl}_{2}+\mathbf{3}$ & $16 \mathrm{~h}$ & NR \\
\hline 7 & AgTFA & $\mathrm{PdCl}_{2}+\mathbf{3}$ & $16 \mathrm{~h}$ & NR \\
\hline 8 & AgOAc & $\mathrm{PdCl}_{2}+\mathbf{3}$ & $16 \mathrm{~h}$ & NR \\
\hline 9 & AgOTf & $\mathrm{PdCl}_{2}+\mathbf{1}$ & $1 \mathrm{~h}$ & 45 \\
\hline 10 & AgOTf & $\begin{array}{c}\mathrm{PdCl}_{2}+\mathrm{DIP}- \\
\operatorname{Im}^{\mathrm{c}}\end{array}$ & $1 \mathrm{~h}$ & NR \\
\hline 11 & AgOTf & $\mathrm{PdCl}_{2}+\mathrm{PPh}_{3}$ & $1 \mathrm{~h}$ & 28 \\
\hline 12 & AgOTf & $\mathrm{PdCl}_{2}+\mathrm{dppe}$ & $1 \mathrm{~h}$ & NR \\
\hline 13 & AgOTf & $\mathrm{PdCl}_{2}+\mathrm{BINAP}$ & $18 \mathrm{~h}$ & NR \\
\hline 14 & AgOTf & $\begin{array}{c}\mathrm{PdCl}_{2}+ \\
\text { DTBM- } \\
\text { SEGPHOS }\end{array}$ & $18 \mathrm{~h}$ & NR \\
\hline 15 & AgOTf & $\begin{array}{c}\mathrm{PdCl}_{2}+c \text {-hex- } \\
\text { diamine }\end{array}$ & $18 \mathrm{~h}$ & NR \\
\hline $16^{\mathrm{d}}$ & AgOTf & $\mathrm{PdCl}_{2}+3$ & $18 \mathrm{~h}$ & NR \\
\hline 17 & AgOTf & 3 & $1 \mathrm{~h}$ & NR \\
\hline
\end{tabular}

a reactions run with $0.5 \mathrm{mmol}$ iodobenzene, $1.25 \mathrm{mmol}$ acetophenone, and $0.025 \mathrm{mmol} 4$ or $\mathbf{5}$, or $10 \%$ ligand and $10 \%$ $\mathrm{PdCl}_{2}$ for in situ reaction at $0.5 \mathrm{M}$ in dioxane. b Conversions determined by ${ }^{1} \mathrm{H}$ NMR of the crude reaction mixture by comparison to an internal standard (isolated yield in parentheses). c DIP-Im $=N$-(2,6-diisopropylphenyl)imidazole. $\mathrm{d}$ With 2 equiv TfOH. 
curred at the less hindered position para to the substituent (6i-61). Only aldehyde functional groups were not tolerated in the reaction $(\mathbf{6 h})$. We were excited to see that an iodoindole gave the corresponding homologated product $(\mathbf{6 q})$ in high yield and that 1,4-diiodobenzene gave the anthracene product in good yield via double cyclization (6r). With all aryl iodide substrates tested, only a single regioisomeric product was observed, which we believe derives from the mechanism of the reaction.

We next investigated the substrate scope of the reaction with respect to the methyl ketone coupling partner (Figure 6). Acetophenone derivatives containing both electron rich and electron poor aromatic rings perform well in the reaction. Substitution at the meta position is well tolerated (11h), but ortho substituents lead to lower isolated yields (11i, 11j). We also investigated the use of dialkyl ketones and found that acetone reacted to give the dimethylnaphthalene derivatives 11k and 111 in modest yield. More hindered ketones such as methyl isobutylketone gave higher yield of the product $(\mathbf{1 1 m}, \mathbf{1 1 n})$. We also

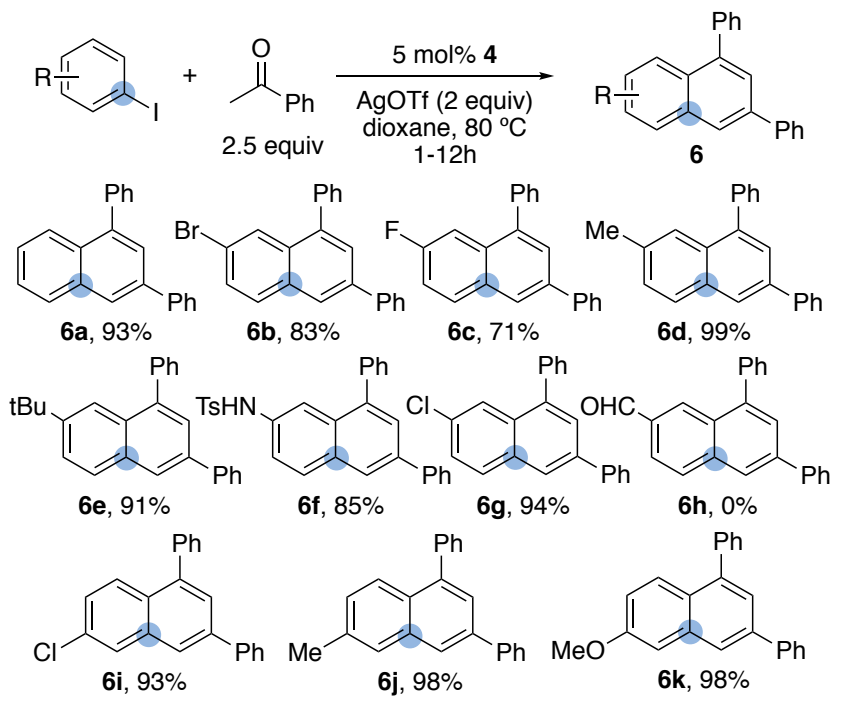<smiles></smiles><smiles></smiles>

$6 p, 91 \%$

$6 q, 70 \%$

Figure 5. Aryl Iodide substrate scope.

tried 3-pentanone and found that the corresponding tetrasubstituted naphthalene could be isolated in modest yield with phenyl iodide (110), but with much higher yield with 4-iodoaniline (11p). 4-Tert-butylcyclohexanone also reacted to give the tetrasubstituted naphthalene in excellent yield $(91 \%, \mathbf{1 1 q})$. Unfortunately, less hindered alkyl ketones such as 2-butanone gave complex mixtures of regioisomeric products.

In order to obtain a better understanding of the mechanism of this reaction and to shed light on the importance of

the bimetallic catalyst's structure, we performed a series of mechanistic experiments (Figure 7). First, we ran the reaction to $50 \%$ conversion and isolated arylated ketone $\mathbf{1 2}$ as a major product present in the reaction (Figure 7a). This intermediate suggests that the reaction proceeds via an initial Pd-catalyzed ketone arylation, followed by addition of a second equivalent of ketone and then cyclization and aromatization. Indeed, we found that when 2-phenylacetophenone (13) was subjected to the standard reaction conditions, product 2a was isolated in $69 \%$ yield (Figure $7 \mathrm{~b}$ ). Interestingly, we also found that palladium catalyst $\mathbf{4}$ was necessary for the cyclization reaction to proceed efficiently, as the reaction with substrate $\mathbf{1 3}$ conducted without the Pd catalyst or with just ligand $\mathbf{3}$ gave only small amounts of product ( $6 \%$ and $19 \%$ yield, respectively). We also conducted a kinetic isotope experiment to better understand the cyclization portion of the mechanism (Figure 7c). When monodeuteroiodobenzene (14) was employed in the reaction, a $k_{\mathrm{H}} / k_{\mathrm{D}}$ of 0.77 was obtained. This inverse secondary kinetic isotope effect suggests that the cyclization step involves rehybridization of an $\mathrm{sp}^{2}$ carbon to an $\mathrm{sp}^{3}$ carbon via a FriedelCrafts-type mechanism, and does not involve a Pd-mediated $\mathrm{C}-\mathrm{H}$ activation event. ${ }^{20}$

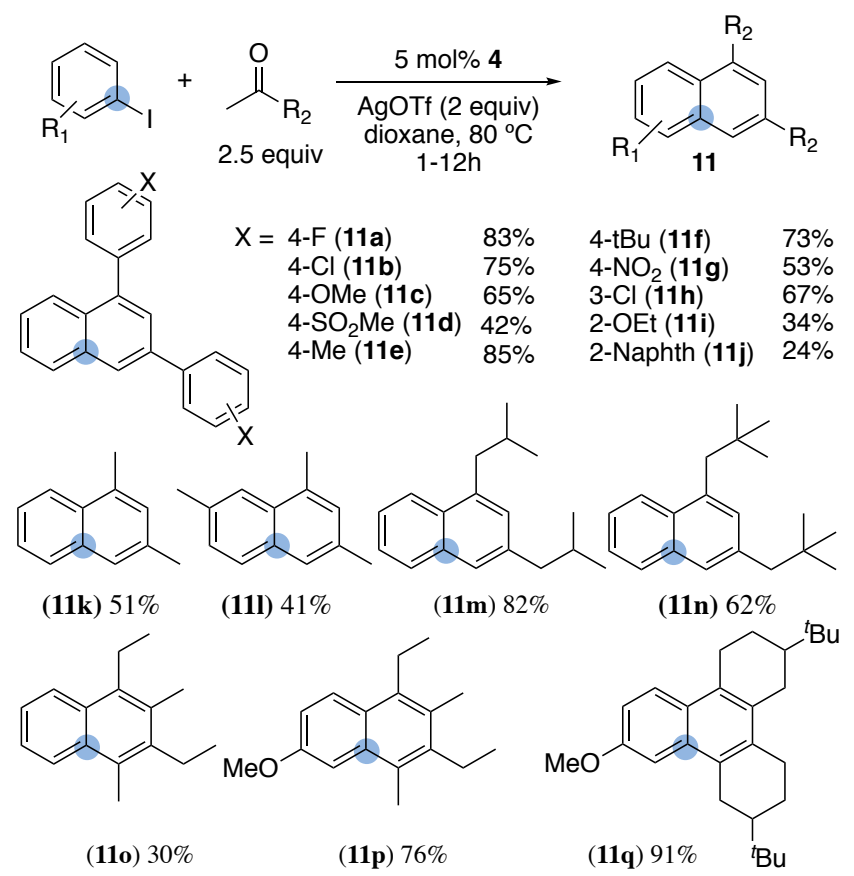

Figure 6. Methyl and dialkyl ketone substrate scope.

One unusual aspect of this new transformation is that the Pd-catalyzed arylation of the ketone to generate intermediate 12 occurs under oxidizing conditions. Typical Pd-catalyzed $\alpha$-arylations of ketones proceed under $\mathrm{Pd}(0) / \mathrm{Pd}(\mathrm{II})$ catalysis in the presence of base via oxidative addition into the aryl iodide. ${ }^{21}$ With bimetallic catalyst $\mathbf{4}$, however, the reaction proceeds under oxidizing conditions (2 equiv $\mathrm{Ag}(\mathrm{OTf})$ ) and the addition of organic or inorganic bases $\left(\mathrm{Et}_{3} \mathrm{~N}, \mathrm{NaOtBu}, \mathrm{Cs}_{2} \mathrm{CO}_{3}\right)$ leads to complete loss of reactivity and no product or ketone arylation are observed (see supporting information for details). In addition, no decrease in the rate or yield is observed when the reaction is run under a balloon of oxygen at $80{ }^{\circ} \mathrm{C}$, which also suggests that the reaction does not proceed via $\mathrm{Pd}(0) / \mathrm{Pd}(\mathrm{II})$ catalysis. 
a)<smiles>CC(=O)c1ccccc1</smiles>
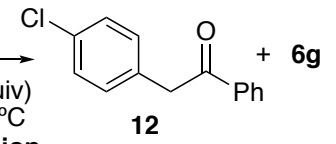

b)

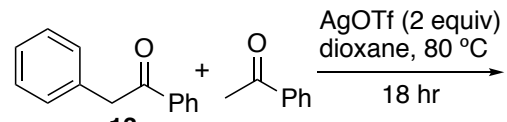

13

c)

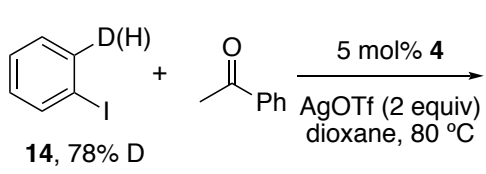

$14,78 \%$ D

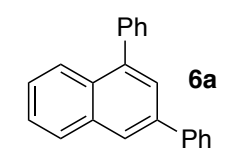

with $5 \mathrm{~mol} \%$ 4, 69\% no catalyst, $\quad 6 \%$ only ligand $3, \quad 19 \%$

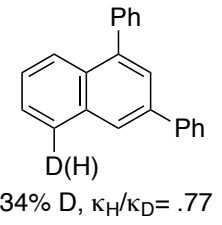

Figure 7. Mechanistic experiments.

We hypothesize that the Pd(II) dimer likely undergoes oxidative addition to the aryl iodide to generate a key palladium(III) dimer intermediate. This pathway would avoid formation of a high energy $\mathrm{Pd}(\mathrm{IV})$ intermediate that results from oxidative addition to a monometallic Pd(II) complex. ${ }^{10}$ To probe this hypothesis, we performed DFT calculations and found that breaking apart the Pd(II) dimer into two monometallic palladium phosphinoimidazole complexes $\left(\mathrm{NPPdCl}_{2}\right)$, followed by oxidative addition to a Pd(IV) intermediate was highly endothermic by $75 \mathrm{kcal} / \mathrm{mol}$, which suggests this type of dissociation and addition pathway is unlikely to occur (Figure 8a). In contrast, the enthalpy required for oxidative addition to the cationic chloridebridged bimetallic complex 15 shown in Figure 8b (to access a Pd(III) dinuclear intermediate) was calculated to be endothermic by only $20.4 \mathrm{kcal} / \mathrm{mol}$. The presence of this
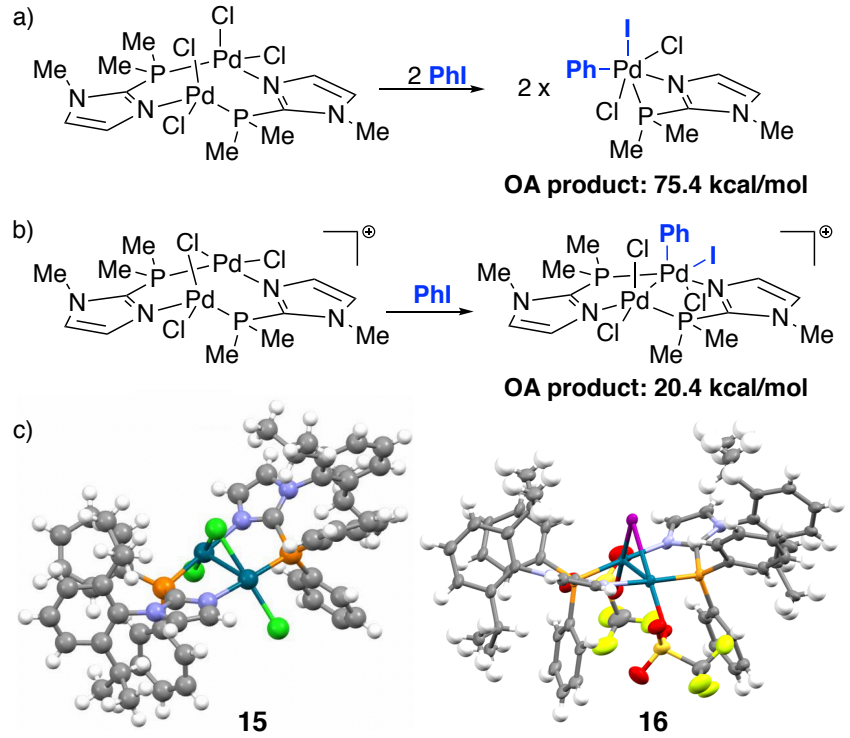

Figure 8. M06/6-31G**[LANL2DZ] DFT-calculated thermodynamic values (enthalpies) for oxidative addition forming a) monometallic Pd(IV) intermediates and b) a bimetallic Pd(III) intermediate. c) X-ray crystal structures of cationic bimetallic complexes containing bridging halides. Anions were omitted for clarity.

type of cationic bridging species is likely in the reaction because we isolated and obtained a crystal structure for this cationic complex, as seen in Figure 8c. The crystal of this bridged halide species was grown under the same conditions as those used to produce complex $\mathbf{4}$, which suggests that 15 may be in equilibrium with 4 in solution. In addition, we subjected our Pd(II) dimer catalyst 4 to phenyl iodide under our reaction conditions and re-isolated and obtained a crystal structure of a bridging iodide species (16) containing two triflate counterions (Figure 8c). The re-isolation of this species suggests that the bimetallic complex remains intact under the reaction conditions, and that oxidative addition and reductive elimination are possible from a bridging halide complex. These studies provide supporting evidence for formation of a $\mathrm{Pd}(\mathrm{III})$ dimer intermediate and confirm the importance of the bimetallic catalyst structure in achieving the unique catalysis observed in this study.

Based on our experimental and computational evidence, we propose the following potential mechanism, as shown in Figure 9. The cycle begins with the bimetallic oxidative addition to the cationic $\mathrm{Pd}^{\mathrm{II}}$ dimer 15 to generate $\mathrm{Pd}(\mathrm{III})$ dimer 17. Enolization of the methyl ketone aided by silver triflate enables transmetallation to install the enolate and aryl group onto the complex (16). At this stage, we are unsure if reductive elimination occurs via a binuclear process where both the enolate and the aryl group are on adjacent metals, or if they occur from an intermediate with both groups on the same metal. Regardless, formation of the arylated ketone intermediate (19) is confirmed by our isolation studies described above. Previously reported work by Ritter and Sanford also confirms that this type of Pd(III) dimer is active in cross coupling reactions under oxidative conditions. ${ }^{10}$ Addition of a second equivalent of the enolate to intermediate 19 would then provide 20 , which then cyclizes via a Friedel-Crafts-type mechanism to give intermediate $\mathbf{2 1}$. Aromatization then occurs via loss of both oxygen functional groups to give the naphthalene product.

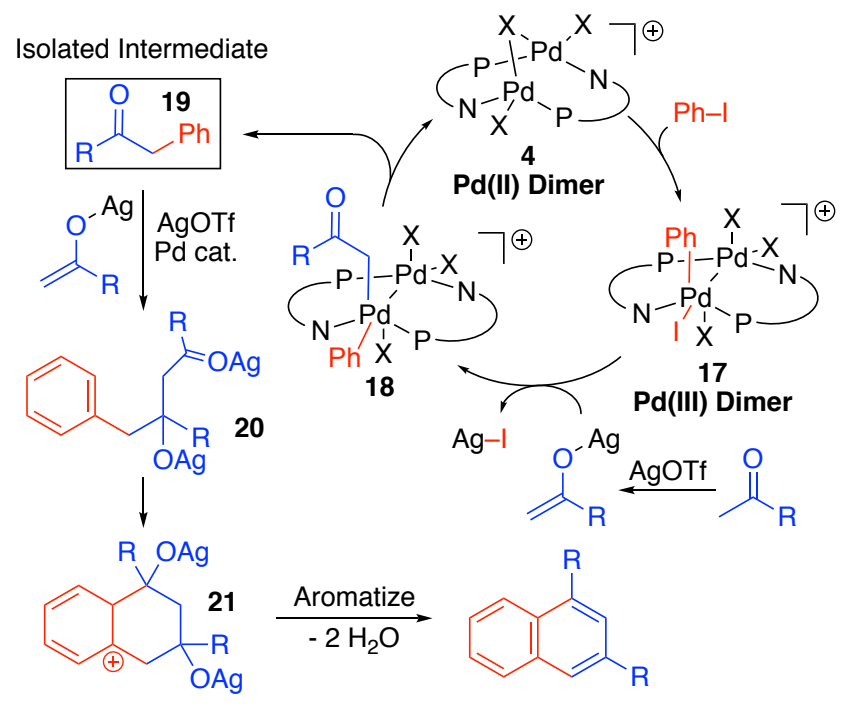

Figure 9. Mechanism of 1,3-naphthalene formation.

Finally, we attempted to couple two different ketone starting materials to generate non-equivalent aryl naphthalenes (Figure 10). Addition of 4-methoxy acetophenone (1 
equiv) and 4-trifluoromethyl acetophenone (6 equiv) to iodobenzene provided product $\mathbf{2 2}$ in $40 \%$ yield. The minor heterocoupled isomer (where the trifluromethylacetophenone added first) was formed in $6 \%$, giving a $6.5: 1$ ratio of isomers. We hypothesized that the electron-deficient ketone would add more rapidly because the lower $\mathrm{pK}_{\mathrm{a}}$ would increase the rate of enolization. However, even when an excess of the trifluoromethylacetophenone was employed (6 equiv), the methoxyacetophenone still underwent arylation faster. We believe that under these reaction conditions, three scenarios are possible: 1) the more electron rich ketone could form a stronger interaction with the silver Lewis acid and thus enolize faster; 2) the more electron-rich enolate binds better to the metal and undergoes faster transmetallation; or 3) the more electron rich enolate helps facilitate faster oxidative addition via precoordination to the Pd(II) dimer.

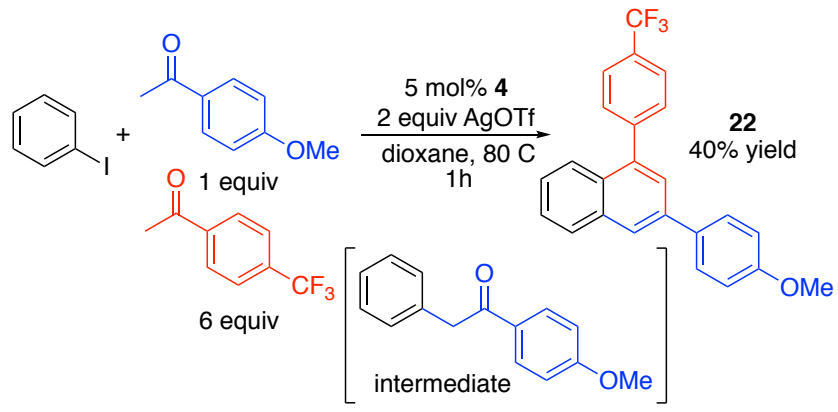

Figure 10. Heterocoupling selectivity in naphthalene synthesis.

In conclusion, we have demonstrated that bimetallic 2phosphinoimidazole-derived $\mathrm{Pd}(\mathrm{I})$ and $\mathrm{Pd}(\mathrm{II})$ complexes enable the formation of 1,3-disubstituted naphthalene derivatives via a ketone arylation/cyclization mechanism. This new transformation provides easy and efficient access to substituted naphthalenes from simple aryl iodides and methyl ketones, and tolerates a range of functional groups at the aryl iodide and methyl ketone partners. The bimetallic structure of the catalyst was also shown to be essential to the observed reactivity, and mechanistic studies confirm the role of the catalyst and the observed selectivity. These results represent a new example of bimetallic catalysis and demonstrate the potential of bimetallic complexes to enable new and more efficient transformations for organic synthesis. Our continuing studies are aimed at investigating the different reactivity profiles for $\mathrm{Pd}(\mathrm{I})$ dimer $\mathbf{4}$ and $\mathrm{Pd}(\mathrm{II})$ dimer $\mathbf{5}$, and in further investigating the cooperative bimetallic mechanism of this reaction.

\section{ASSOCIATED CONTENT}

\section{Supporting Information}

The Supporting Information is available free of charge from the corresponding author.

Experimental procedures, characterization data, spectral images (PDF).

X-ray crystallographic data (CIF)

\section{AUTHOR INFORMATION}

\section{Corresponding Author}

*dmichaelis@chem.byu.edu

${ }^{\dagger}$ Current Locations: S.H.N - Acme Bioscience Inc. 3941 East Bayshore Rd, Palo Alto, California 94303. G.A.V.-B. - Material and Analytical Sciences, Boehringer Ingelheim Pharmaceuticals, Inc., Ridgefield, Connecticut 06877.

\section{ACKNOWLEDGMENT}

D.J.M acknowledges the donors of the American Chemical Society Petroleum Research Fund for support of this research (PRF No. 56371-DNI1). D.J.M also acknowledges financial support provided by the Chemical Catalysis Program of the National Science Foundation (CHE-1665015). D.H.E. acknowledges the United States National Science Foundation Chemical Catalysis Program for support (CHE-1764194) and the National Science Foundation Chemical Structure, Dynamics, and Mechanisms B (CSDM-B) Program for support under award CHE 1952420. We thank Brigham Young University and the Office of Research Computing, especially the Fulton Supercomputing Lab. We thank Jimmy Coombs for help with DFT calculations and discussions.

\section{REFERENCES}

(1) (a) Farley, C. M.; Uyeda, C. Organic Reactions Enabled by Catalytically Active Metal-Metal bonds. Trends in Chem. 2019, 1(5), 497-509. (b) Powers, I. G.; Uyeda, C. Metal-Metal Bonds in Catalysis. ACS Catal. 2017, 7, 936-958. (c) Pye, D. R.; Mankad, N. P. Bimetallic Catalysis for $\mathrm{C}-\mathrm{C}$ and $\mathrm{C}-\mathrm{X}$ Coupling Reactions. Chem. Sci. 2017, 8, 1705-1718. (d) Cooper, B. G.; Napoline, J. W.; Thomas, C. W. Catalytic Applications of Early/Late Heterobimetallic Complexes. Catal. Rev. 2012, 54, 1-40. (e) Ritleng, V.; Chetcuti, M. J. Chem Rev. 2007, 107, 797-858.

(2) Nakamura, E.; Yoshikai, N.; Yamanaka, M. Mechanism of C-H Bond Activation/C-C Bond Formation Reaction Between Diazo Compound and Alkane Catalyzed by Dirhodium Tetracarboxylate. J. Am. Chem. 2002, 124(24), 7181-7192.

(3) (a) Mazzacano, T. J.; Mankad, N. P. "Base Metal Catalysts for Photochemical C-H Borylation That Utilize Metal-Metal Cooperativity." J. Am. Chem. Soc. 2013, 135, 17258-17261. (b) Leon, N. J; Yu, H. C.; Mazzacano, T. J.; Mankad, N. P. Pursuit of C-H borylation reactions with non-precious heterobimetallic catalysts: hypothesisdriven variations on a design theme Synlett 2020; 31, 125-132

(4) (a) Cammarota, R. C.; Lu, C. C. Tuning Nickel with Lewis Acidic Group 13 Metalloligands for Catalytic Olefin Hydrogenation. J. Am. Chem. Soc. 2015, 137, 12486-12489. (b) Ramirez, B. L.; Sharma, P.; Eisenhart, R. J.; Gagliardi, L.; Lu, C. C. Bimetallic nickellutetium complexes: tuning the properties and catalytic hydrogenation activity of the Ni site by varying the Lu coordination environment. Chem. Sci. 2019, 10, 3375-3384. (c) Ramirez, B. L.; Lu, C. C. Rare-earth supported nickel catalysts for alkyne semihydrogenation: chemo- and regioselectivity impacted by the Lewis acidity and size of the support. J. Am. Chem. Soc. 2020, 142, 5396-5407.

(5) (a) Zhou, Y. -Y.; Uyeda, C. Catalytic reductive [4+1]-cycloadditions of vinylidines and dienes Science 2019, 363, 857-862. (b) Pal, S.; Zhou, Y.-Y.; Uyeda, C. Catalytic Reductive Vinylidene Transfer Reactions. J. Am. Chem. Soc. 2017, 139, 11686-11689. (c) Pal, S.; Uyeda, C. Evaluating the Effect of Catalyst Nuclearity in Ni-Catalyzed Alkyne Cyclotrimerizations. J. Am. Chem. Soc. 2015, 137, 8042-8045

6 (a) Tsutsumi, H.; Sunada, Y.; Shiota, Y.; Yoshizawa, K.; Nagashima, H. Nickel(II), Palladium(II), and Platinum(II) ๆ3-Allyl 
Complexes Bearing a Bidentate Titanium(IV) Phosphinoamide Ligand: A Ti $\leftarrow$ M2 Dative Bond Enhances the Electrophilicity of the $\pi-$ Allyl Moiety. Organometallics 2009, 28, 1988-1991. (a) Walker, W. K.; Anderson, D. L.; Stokes, R. W.; Smith, S. L.; Michaelis, D. J. Allylic Aminations with Hindered Secondary Amine Nucleophiles Catalyzed by Heterobimetallic Ti-Pd Complexes. Org. Lett. 2015, 17, 752-755. (b) Walker, W. K.; Kay, B. M.; Michaelis, S. A.; Anderson, D. L.; Smith, S. J.; Ess, D. H.; Michaelis, D. J. Origin of Fast Catalysis in Allylic Amination Reactions Catalyzed by Pd-Ti Heterobimetallic complexes. J. Am. Chem. Soc. 2015, 137, 7371-7378. (c) Ence, C.; Walker, W. K.; Martinez, E.; Stokes, R. W.; Sarager, S.; Smith, S. J.; Michaelis, D. J. Synthesis of chiral titanium-containing phosphinoamide ligands for enantioselective heterobimetallic catalysis. Tetrahedron 2019, 75, 3341-3347.

(7) Inatomi, T.; Koga, Y.; Matsubara, K. Dinuclear Nickel(I) and Palladium(I) Complexes for Highly Active Transformations of Organic Compounds. Molecules 2018, 23, 140.

(8) Parmelee, S. R.; Mazzacano, T. J.; Mankad, N. P.*; Keith, J. A.* A Heterobimetallic Mechanism for C-H Borylation Elucidated from Experimental and Computational Data. ACS Catal. 2015, 5, 36893699.

(9) Powers, D. C.; Ritter, T. Bimetallic Redox Synergy in Oxidative Palladium Catalysis. Acc. Chem. Res. 2012, 45, 840-850.

(10) (a) Powers, D. P; Ritter, T. Bimetallic Pd(III) Complexes in Palladium-Catalyzed Carbon-Heteroatom Bond Formation" $\mathrm{Na}$ ture Chem. 2009, 1, 302-309. (b) D. C. Powers, T. Ritter "Bimetallic redox synergy in oxidative palladium catalysis" Acc. Chem. Res. 2012, 45, 840-850. (c) Powers, D. C.; Lee, E.; Ariafard, A.; Sanford, M. S.; Yates, B. F.; Canty, A. J.; Ritter, T. Connecting Binuclear PdIII and Mononuclear PdIV Chemistry by Pd-Pd Bond Cleavage," J. Am. Chem. Soc. 2012, 134, 12002-12009. (d) Canty, A. J.; Ariafard, A.; Sanford, M. S.; Yates, B. F. Mechanism of Pd-Catalyzed Ar-Ar Bond Formation Involving Ligand-Directed $\mathrm{C}-\mathrm{H}$ Arylation and Diaryliodonium Oxidants: Computational Studies of Orthopalladation at Binuclear PdII Centers, Oxidation To Form Binuclear Palladium (III) Species, and Ar..Ar Reductive Coupling. Organometallics 2013, 32, 544-555. (e) Powers, D. C.; Ritter, T. A Transition State Analogue for the Oxidation of Binuclear Palladium(II) to Binuclear Palladium(III) Complexes. Organometallics 2013, 32, 2042-2045.

(11) Inatomi, T.; Koga, Y.; Matsubara, K. Dinuclear Nickel(I) and Palladium(I) Complexes for Highly Active Transformations of Organic Compounds. Molecules 2018, 23, 140.

(12) (a) Díez, V.; Espino, G.; Jalón. F. A.; Manzano, B. R.; PérezManrique, M. Synthesis and structure of new palladium complexes with the ligand 2-(diphenylphosphino)-1-methylimidazole: Evidence of hemilability. J. Organomet. Chem. 2007, 692, 1482-1495. (b) Done, M. C.; Rüther, T.; Cavell, K. J.; Kilner, M.; Peacock, E. J.; Braussaud, N.; Skelton, B. W.; White, A. Novel cationic and neutral Pd(II) complexes bearing imidazole based chelate ligands: synthesis, structural characterisation and catalytic behaviour. J. Organomet. Chem. 2000, 607, 78-92. (c) An imidazole-based P-N bridging ligand and its binuclear copper(I), silver(I) and palladium(I) complexes: synthesis, characterizations and X-ray structures. Polyhedron 2001, 20, 627-633.

(13) Martinez, E. E.; Jensen, C. A.; Larson, A. J. S.; Kenney, K. C.; Clark, K. J.; Nazari, S. H.; Valdivia-Berroeta, G. A.; Smith, S. J.; Ess, D. H.; Michaelis, D. J.; Monosubstituted, Anionic (Imidazolyl) N-Heterocyclic Carbene Complexes of Palladium and Their Activity in Cross-Coupling Reactions. Adv. Synth. Catal. 2020, 362, 28762881.

(14) ${ }^{1}$ (a) Frisch, M. J.; Trucks, G. W.; Schlegel, H. B.; Scuseria, G. E.; Robb, M. A.; Cheeseman, J. R.; Scalmani, G.; Barone, V.; Petersson, G. A.; Nakatsuji, H.; Li, X.; Caricato, M.; Marenich, A. V.; Bloino, J.; Janesko, B. G.; Gomperts, R.; Mennucci, B.; Hratchian, H. P.; Ortiz, J. V.; Izmaylov, A. F.; Sonnenberg, J. L.; Williams; Ding, F.; Lipparini,
F.; Egidi, F.; Goings, J.; Peng, B.; Petrone, A.; Henderson, T.; Ranasinghe, D.; Zakrzewski, V. G.; Gao, J.; Rega, N.; Zheng, G.; Liang, W.; Hada, M.; Ehara, M.; Toyota, K.; Fukuda, R.; Hasegawa, J.; Ishida, M.; Nakajima, T.; Honda, Y.; Kitao, O.; Nakai, H.; Vreven, T.; Throssell, K.; Montgomery Jr., J. A.; Peralta, J. E.; Ogliaro, F.; Bearpark, M. J.; Heyd, J. J.; Brothers, E. N.; Kudin, K. N.; Staroverov, V. N.; Keith, T. A.; Kobayashi, R.; Normand, J.; Raghavachari, K.; Rendell, A. P.; Burant, J. C.; Iyengar, S. S.; Tomasi, J.; Cossi, M.; Millam, J. M.; Klene, M.; Adamo, C.; Cammi, R.; Ochterski, J. W.; Martin, R. L.; Morokuma, K.; Farkas, O.; Foresman, J. B.; Fox, D. J. Gaussian 16 Rev. B.01, Wallingford, CT, 2016. (b) Zhao, Y.; Truhlar, D. G., The M06 Suite of Density Functionals for Main Group Thermochemistry, Thermochemical Kinetics, Noncovalent Interactions, Excited States, and Transition Elements: Two New Functionals and Systematic Testing of Four M06-class Functionals and 12 Other Functionals. Theoretical Chemistry Accounts 2008, 120, 215-241.

(15) All structures were reoptimized from the starting crystal structure with the M06 functional using the 6-31G**[LANL2DZ for Pd] basis set in Gaussian 16. Structures were confirmed as minima or transition states by vibrational frequency analysis. Reported enthalpies correspond to $298 \mathrm{~K}$ and $1 \mathrm{~atm}$ using the default thermochemistry in Gaussian 16. The SMD solvent model for dioxane was used in all calculations.

(16) For recent examples, see: (a) Hein, S. J.; Lehnherr, D.; Arslan, H.; Uribe-Romo, F. J.; Dichtel, W. R. Alkyne Benzannulation Reactions for the Synthesis of Novel Aromatic Architectures. Acc. Chem. Res. 2017, 50, 2776-2778. (b) Yu, L.-Z.; Wei, Y.; Shi, M. Synthesis of Polysubstituted Polycyclic Aromatic Hydrocarbons by Gold-Catalyzed Cyclization-Oxidation of Alkylidenecyclopropane-Containing 1,5-Enynes. ACS Catal. 2017, 7, 4242-4247. (c) Yadav, S.; Hazra, R.; Singh, A.; Ramasastry, S. S. V. Substituent-Guided Palladium-Ene Reaction for the Synthesis of Carbazoles and Cyclopenta[b]indoles. Org. Lett. 2019, 21, 2983-2987. (d) Dal Zotto, C.; Wehbe, J.; Virieux, D.; Campagne, J.-M. FeCl3-Catalyzed Intramolecular Hydroarylation of Alkynes. Synlett 2008, 1, 2033-2035. (e) Kabalka, G. W.; Ju, Y.; Wu, Z. A New Titanium Tetrachloride Mediated Annulation of $\alpha$ Aryl-Substituted Carbonyl Compounds with Alkynes: A Simple and Highly Efficient Method for the Regioselective Synthesis of Polysubstituted Naphthalene Derivatives. J. Org. Chem. 2003, 68, 7915-7917.

(17) Makar, S.; Saha, T.; Singh, S. K. Naphthalene, a versatile platform in medicinal chemistry: Sky-high perspective. Eur. J. Med. Chem. 2019, 161, 252-276.

(18) Mulembo, T.; Nagai, G.; Tamagawa, H.; Nitta, T.; Sasaki, $\mathrm{M}$. Conductive and flexible multi-walled carbon nanotube/polydimethylsiloxane composites made with naphthalene/toluene mixture. J. Appl. Polym. Sci. 2019, 136(44), 48167.

(19) Shudo, Y.; Karium, M. R.; Ohtani, R.; Nakamura, M. Hybrids from the $\pi-\pi$ stacking of graphene oxide and aromatic sulfonic compounds for improved proton conductivity. ChemElectroChem. 2018, 5, 238.

(20) Park, H.; Yoo, K.; Jung, B.; Kima, M. Direct Synthesis of Anthracenes from o-Tolualdehydes and Aryl Iodides through Pd(II)Catalyzed $s p^{3} \mathrm{C}-\mathrm{H}$ Arylation and Electrophilic Aromatic Cyclization. Tetrahedron 2018, 74, 2048-2055.

(21) (a) Culkin, D. A.; Hartwig, J. F. Palladium-Catalyzed $\alpha$-Arylation of Carbonyl Compounds and Nitriles. Acc. Chem. Res. 2003, 36, 234-245. (b) Stradiotto, M. Ancillary ligand design in the development of palladium catalysts for challenging selective monoarylation reactions. RSC Catalysis Series (2015), 21, (New Trends in Cross-Coupling), 228-253. 


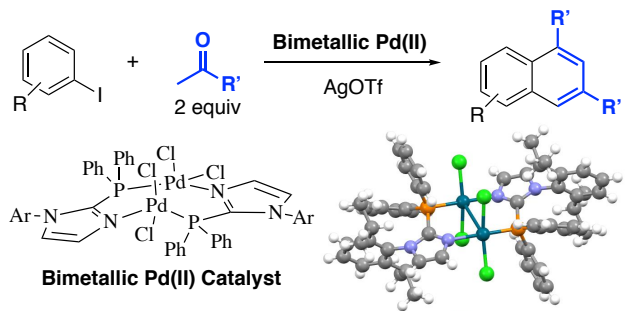

